REVIEW

\title{
Influenza burden of illness, diagnosis, treatment, and prevention: what is the evidence in children and where are the gaps?
}

\author{
S S S Teo, J S Nguyen-Van-Tam, R Booy
}

Arch Dis Child 2005;90:532-536. doi: 10.1136/adc.2004.051896

Influenza is a disease of global public health significance. Traditionally the emphasis has been on adult disease because of the impact of influenza related mortality in the elderly and other high risk groups. However, it is becoming increasingly better recognised that young children suffer considerable morbidity from influenza. ${ }^{1-6}$ There are also potential consequences for siblings, parents, other carers, and extended family members in terms of secondary infections and carer leave. Influenza infection in childhood could be effectively prevented through vaccination.

However, the United States is the only industrialised country currently recommending universal influenza vaccination for young children (between the ages of 6 and 23 months), as opposed to vaccinating only those with high risk conditions. ${ }^{7} 8$

See end of article for authors' affiliations .....................

Correspondence to: Prof. R Booy, Centre for Child Health, Queen Mary's School of Medicine and Dentistry at Barts and the London, University of London, UK; r.booy@ qmul.ac.uk

Accepted8December 2004
$\mathrm{T}$ his paper discusses the burden of influenza in children, its economic impact, the availability of diagnostic tests, and their place in clinical practice, along with the role of antiviral therapy. We describe current recommendations for influenza vaccination and highlight where more evidence would be helpful.

\section{BIOLOGY OF INFLUENZA}

Influenza viruses are classified as type A, B, or C. ${ }^{9-11}$ Clinically, influenza A and B infections are not readily distinguishable, both producing seasonal epidemics, whereas influenza $\mathrm{C}$ produces a milder coryzal illness. ${ }^{11}$ Type A influenza viruses are further divided into subtypes based on variation in haemagglutinin and neuraminidase surface antigens. ${ }^{11}$ The nomenclature of influenza viruses describes type, geographical origin, strain number, year first isolated and subtype, for example A/New Caledonia/20/99 (HINl).12 ${ }^{13}$ So far only influenza A viruses containing $\mathrm{H} 1, \mathrm{H} 2$, or $\mathrm{H} 3$ and $\mathrm{Nl}$ or $\mathrm{N} 2$, and influenza B have caused widespread human disease..$^{10}$ Only influenza A has the propensity to cause pandemic influenza. ${ }^{911}$

\section{BURDEN OF INFLUENZA IN CHILDREN}

Attack rates of influenza are higher among preschool and school age children than in any other age group. ${ }^{314}{ }^{15}$ The likelihood of residual cross-immunity from previous influenza infection is directly proportional to age. ${ }^{11}$ There is a growing body of evidence that influenza in children produces a heavy burden in terms of primary care consultations, hospitalisations, and the use of antibiotics and over-the-counter medications. ${ }^{156}$ Relevant European data are also accumulating. ${ }^{4}{ }^{16-18}$ In contrast the elderly suffer by far the highest mortality from influenza, especially during inter-pandemic periods. ${ }^{319}$ It is worthy of note, however, that mortality in those younger than 19 years of age has accounted for up to $12 \%$ of deaths due to pneumonia or influenza during some influenza epidemics. ${ }^{20}$ During the 2003-04 influenza season there were 143 influenza related paediatric deaths documented in the USA; about $40 \%$ of these were younger than 2 years, highlighting the high vulnerability of this age group. ${ }^{7}$ In addition, almost one half of victims aged 2-17 years did not have an underlying high risk condition. ${ }^{7}$ Paediatric influenza related deaths were also widely reported in the media in the $\mathrm{UK}^{21}$ and at least 12 were confirmed. ${ }^{22}$ Because day care attendance has risen considerably in recent times, ${ }^{23}$ opportunities for exposure and transmission may be greater than ever before in preschool children. These children are at high risk of respiratory infection ${ }^{24}$ and may account for substantial health expenditure. ${ }^{25}$ They may also be among the first infected during a community influenza outbreak. ${ }^{3}$

\section{ROLE OF CHILDREN IN THE TRANSMISSION OF INFLUENZA}

Studies conducted over 25 years ago showed than influenza spreads within families with secondary attack rates of up to $30 \%$. Preschool and school age children were major introducers of influenza infection into communities. ${ }^{26-28}$ However, with increased use of day care, ${ }^{23}$ preschool age children may have become an even more important source of community transmission. There is also growing evidence that influenza vaccination is effective in interrupting transmission within families and communities. A single blind randomised controlled trial found that school age household contacts of influenza vaccinated day care children had significantly fewer respiratory illnesses, less school absenteeism, fewer physician visits, and lower use of antibiotics and over-the-counter medications than did contacts of unvaccinated children. ${ }^{29}$ Similar results were achieved in an open labelled study in Italy. ${ }^{18}$ The community impact of childhood influenza vaccination was shown during the 1968-69 influenza season in 
Tecumseh, Michigan. A high vaccination rate among schoolchildren (about 85\%) was associated with a threefold decrease in respiratory illnesses in the wider community compared with the rate in an unvaccinated community nearby. ${ }^{30}$ In addition, population based findings from Japan suggest that a statutory programme of influenza vaccination of schoolchildren (from the 1960s through to the early 1990s) led to a significant decrease in winter season pneumonia and influenza and all-cause mortality, especially in the elderly. When the programme was subsequently discontinued, winter seasonal mortality increased. ${ }^{31}$ However, an increase in the elderly population may have confounded these findings. ${ }^{32}$ Our understanding of the direct and indirect effects of childhood influenza vaccination should be improved. Modelling would be helpful, as would a cluster randomised double blind controlled trial among day care children and their families. ${ }^{33}$ If the vaccination of day care children is shown to substantially benefit both vaccinees and their close contacts, through reducing transmission and the incidence of influenza-like illness, this could form part of the justification for universal vaccination of preschool aged children against influenza.

\section{ECONOMIC BURDEN OF CHILDHOOD INFLUENZA INFECTION}

Influenza is associated with considerable economic costs to families, healthcare services, and society. When a child is symptomatic with influenza, costs may be incurred in terms of physician visits, medications, and parental absence from work. Transmission of influenza in the household may lead to parental time off work or parental illness that produces onward transmission in the workplace and in turn reduced productivity. Influenza vaccination of working adults and the elderly against influenza is both clinically and cost effective. ${ }^{34}$ Vaccination of children is efficacious ${ }^{35-37}$ and may well be cost effective. $^{3438}$ No large scale randomised trial has yet evaluated the wider impact of routinely vaccinating children in terms of healthcare and other economic costs. Broadening the scope of influenza vaccination to include children would have the secondary benefit of increasing annual interpandemic usage, thereby increasing manufacturing capacity which would be needed in the event of a future pandemic. ${ }^{39}$

\section{DIAGNOSTIC TESTS}

Having an influenza-like illness has low specificity. Consequently specific tests performed in the laboratory are helpful. Recommended clinical samples include a nasal aspirate, nasal wash, and a nose or throat swab. ${ }^{40}{ }^{41}$ Direct and indirect fluorescent antibody testing (DFA and IFA) are both widely available and have high specificity, albeit with lower sensitivity. In comparison with viral culture, studies of the sensitivity of DFA for influenza A showed a median sensitivity of $62 \%{ }^{42}$ The addition of polymerase chain reaction facilitates more sensitive diagnosis of influenza but requires specialised skills and is expensive. Presently it takes 1-2 days. ${ }^{43}$ In contrast, rapid diagnostic, or near patient testing is clinically available and can produce a diagnosis within 30 minutes. Some kits also allow differentiation of influenza A from influenza B. ${ }^{40}{ }^{42}$ Rapid tests have been evaluated in both children and adults. Again the specificity is high with varying but generally moderate sensitivity. ${ }^{40}{ }^{42}$ The results of rapid diagnostic tests should always be interpreted against the background of clinical symptoms, the level of influenza activity in the community (epidemiological and virological surveillance data), and the presence of any high risk conditions in the patient. The use of near-patient tests has been associated with a reduction in investigations ordered and antibiotics prescribed in the emergency department setting. ${ }^{44}{ }^{45}$ They are most useful in the investigation of outbreaks of respiratory disease or guiding decisions as to whether to commence antiviral therapy, ${ }^{11}$ especially in severely ill children. In the clinical setting, a positive DFA, IFA, or rapid diagnostic test will have the highest positive predictive value when influenza activity in the surrounding community is high. ${ }^{42}$ However, it should be noted that a positive diagnostic test for influenza does not exclude bacterial co-infection; and influenza may predispose to serious secondary bacterial pneumonia. ${ }^{46}{ }^{47}$

\section{ANTIVIRAL TREATMENT}

In the absence of routine vaccination in children, antiviral treatment deserves consideration both for its therapeutic effect and its impact on disease transmission. During the 2003-04 northern hemisphere influenza season the combination of a clinically significant drift variant and shortages in vaccine supply, for example in the USA $^{48}$ threw into sharp relief the role of antivirals. They may be useful when there is a vaccine shortage during an inter-pandemic period and are likely to be of use in the first wave of a pandemic to contain spread from initial cases, and to protect healthcare workers when vaccine is either unavailable or in extremely short supply. Antivirals for influenza include two neuraminidase inhibitors (NAIs), oseltamivir and zanamivir (inhaled drug not recommended in children $<12$ years), and two M2 inhibitors, amantadine (not licensed in children $<10$ years in the UK) and rimantadine (not licensed in UK). ${ }^{49}$

The M2 inhibitors are not effective against influenza B..$^{51}$ In addition, when used for treatment and prophylaxis in the same setting they are likely to lead to the rapid emergence of resistant viruses which are transmissible person-to-person. ${ }^{52}{ }^{53}$ NAIs can reduce the chances of developing influenza by $70-90 \%$ in adults. ${ }^{54}$ However, there is currently judged to be insufficient evidence for using an NAI for prophylaxis in children. ${ }^{54}$ When used in treatment, NAIs reduce the duration of symptoms by up to two days. ${ }^{42} 5455$ The use of oseltamivir in children has also been associated with a reduction in the use of antibiotics, ${ }^{56}$ but evidence for a reduction in hospitalisation has so far been obtained only in adults. ${ }^{57}$ When used for treatment or prophylaxis, both M2 inhibitors and NAIs should be started within 48 hours after the onset of illness or exposure, respectively. ${ }^{42} 49505859$ The NAIs have a considerably better adverse event profile than the M2 inhibitors, ${ }^{10}{ }^{50}$ although oseltamivir is sometimes associated with vomiting. ${ }^{56}$ Guidelines have been set out by the Centers for Disease Control (CDC) in the USA and the National Institute for Clinical Excellence (NICE) in the UK (boxes 1 and 2). 49515859

The cost effectiveness of antiviral therapy is less clear than for vaccination. ${ }^{38}$ In addition, delivering timely treatment to a large number of children during the 8-12 week period of an influenza epidemic presents obvious logistic challenges. The problem for clinicians in deciding how best to use antivirals in the context of official guidelines is made more difficult by the lack of controlled trials of antiviral therapy in children less than 1 year old, immunocompromised children, and those with serious influenza related complications. ${ }^{42}$ However there is a consensus that, during periods of known community influenza activity, antivirals should be considered for the treatment of high risk children with influenza-like illness providing treatment can be started within 48 hours of the onset of symptoms, ${ }^{49}$ and for seriously ill children in hospital. $^{58}$

\section{INFLUENZA VACCINES}

While inactivated and cold adapted, live attenuated influenza vaccines are both regarded as safe and effective,, 3536 only inactivated vaccines are currently licensed in the UK. ${ }^{61}$ Inactivated influenza vaccines comprise either split virion 
Box 1: Guidelines on the use of antivirals in the treatment of influenza

NICE: When influenza is circulating, patient is high risk, has an influenza-like illness, and can start within 48 hours of the onset of symptoms ${ }^{49}$

- Zanamivir: $\geqslant 12$ years old

- Oseltamivir: child (lower age limit not specified)

- Amantadine is not recommended for treatment of influenza

$\mathrm{CDC}^{51} 58$

- Zanamivir if age $\geqslant 7$ years

- Oseltamivir if age $\geqslant 1$ year

- Amantadine for influenza $A$ if age $\geqslant 1$ year

- Rimantadine for influenza $A$ in adults only

In institutions or other closed communities with many high risk individuals, should be used for treating persons who have been ill with influenza for $<48$ hours

Antiviral drugs should also be considered for the treatment of:

- High risk persons aged $\geqslant 1$ year with influenza infection $<48$ hours after the onset of illness

- Seriously ill influenza infected hospital patients

- Family members of high risk individuals during local community influenza activity

- Low risk influenza infected individuals if adequate antiviral drug supplies

(virus particles disrupted by detergent treatment), subunit (haemagglutinin and neuraminidase surface antigens), or virosomal (surface antigens combined with phospholipids to produce virosomes) formulations. ${ }^{1262-64}$ There is no established preference as to which type should be administered in children, although thiomersal-free formulations are clearly desirable. $^{762}$ Meta-analysis has shown that the inactivated and live vaccines are of comparable efficacy in children, ${ }^{37}$ although, if anything, the inactivated is slightly better. Despite evidence of safety from clinical trials, some experts have expressed theoretical concerns that the live intranasal vaccine could genetically reassort in the presence of coinfection to a more virulent strain. ${ }^{37}$ The efficacy of influenza immunisation depends on a number of factors including the age of the vaccinee and the antigenic match between vaccine and circulating strains. ${ }^{35}$ Achieving the latter is not always a straightforward process. For example, the circulating influenza $\mathrm{A}(\mathrm{H} 3 \mathrm{~N} 2)$ strain in the winter of $2003-04$ was an $\mathrm{A} /$ Fujian/411/2002/like drift variant, ${ }^{65}$ but it could not be grown readily in embryonated eggs in time to use as a seed virus in vaccine manufacture. ${ }^{13}$ Since virological studies had shown that the Fujian-like strain was antigenically related to A/ Panama/2007/99, ${ }^{66}$ which was widely used in the 2002-03 northern hemisphere season, the latter was used again in 2003-04, even though it was not regarded as an ideal match. For the southern hemisphere winter of 2004 a Fujian-like drift variant was developed, ${ }^{13}$ and this has also been incorporated into the northern hemisphere 2004-05 winter vaccine (H1Nl: A/New Caldedonia/20/99-like; H3N2: A/ Fujian/411/2002-like; influenza B: B/Shanghai/361/2002like). ${ }^{67}$
Box 2: Guidelines for the use of antivirals for prophylaxis against influenza

NICE: When influenza is circulating, patient is high risk, has an influenza-like illness, and can start within 48 hours of the onset of symptoms ${ }^{59}$

Oseltamivir:

- Age $\geqslant 13$ years, and

- Exposed to an individual with an influenza-like illness, and

- Either (a) Not effectively protected by vaccination, that is

- Not vaccinated, or

- Vaccination yet to take effect, or

- Vaccine strain not well matched to the circulating strain

or (b) Lives in residential care, regardless of vaccination status

Amantadine not recommended for prophylaxis

$\mathrm{CDC}^{51} 58$

- Oseltamivir: if patient $\geqslant 13$ years

- Zanamivir not approved for prophylaxis

- Amantadine and rimantadine approved for prophylaxis of influenza $A$ if age $\geqslant 1$ year

These should be used for outbreaks in institutions or other closed communities with many high risk individuals for prophylaxis for both residents/patients and unvaccinated employees who are contacts during the outbreak.

Antiviral chemoprophylaxis should also be considered for:

- High risk persons $\geqslant 1$ year of age during outbreaks in closed communities or even in the wider community

- Unvaccinated healthcare workers in close contact with influenza infected patients

- Seriously ill influenza infected hospital patients

- Family members of high risk individuals during local community influenza activity

- Low risk influenza infected individuals if adequate antiviral supplies

\section{RECOMMENDATIONS FOR USE OF INFLUENZA \\ VACCINES}

When children who have not been previously exposed to influenza receive the influenza vaccine for the first time, they are immunologically naïve and immunogenicity is suboptimal. This mainly holds true for young children and is the reason why children under 13 years who are being vaccinated for the first time should receive two doses separated by 46 weeks. ${ }^{68}$ Annual influenza vaccination is recommended for certain risk groups in many countries of the world, for example by the Advisory Committee on Immunization Practices (ACIP) in the USA and the Department of Health in the UK. These recommendations include persons aged 65 years and over, persons with chronic conditions of the lungs, heart, or kidneys, diabetes mellitus, immunosuppression, and anyone living in long term residential accommodation. Children with high risk conditions are included, ${ }^{762}$ but 
uptake is poor, especially where physicians do not proactively recommend the injection. ${ }^{69}$ With effect from autumn 2002, annual influenza immunisation for children in the USA between 6 and 23 months of age was "encouraged when feasible" by ACIP. ${ }^{11}$ This advice was recently upgraded for the 2004-05 winter season to a full ACIP recommendation. ${ }^{7}$ In contrast, healthy European children and their household contacts are not currently recommended for immunisation, ${ }^{70}$ although the subject is under investigation in some countries. More needs to be known about likely parental acceptance of annual influenza vaccination for children in Europe if policy were to change.

\section{CONCLUSION}

Children suffer substantial morbidity from influenza. However, most of the evidence is from the USA and more needs to be understood regarding the burden of disease in European countries and elsewhere in the world. Rapid diagnostic tests may be useful in detecting outbreaks or when deciding to whether to start antiviral drugs in high risk patients. During known periods of community influenza activity, antiviral therapy should be given to high risk children suffering an influenza-like illness, within 48 hours of the onset of symptoms, even without laboratory confirmation, and should be considered in any child who is seriously ill with an influenza-like illness. The inactivated vaccine is safe and effective. Universal infant influenza vaccination has been recommended in the USA but not yet elsewhere. More needs to be known about the likely parental acceptance of annual vaccination of children and stronger evidence needs to be generated for the clinical and cost effectiveness of vaccination, for children in terms of direct benefit, and indirectly regarding effects on the wider community. If so, a case might be established for other developed countries to emulate the ACIP recommendation.

\section{ACKNOWLEDGEMENTS}

We thank Maria Zambon, David Fedson, and David McIntosh for their thoughtful comments.

\section{Authors' affiliations}

S S S Teo, R Booy, Centre for Child Health, Queen Mary's School of Medicine and Dentistry at Barts and the London, University of London, UK

\section{J S Nguyen-Van-Tam, Aventis Pasteur MSD, Maidenhead, UK}

Competing interests: ST and RB are in receipt of grant-in-aid from Wyeth for influenza research. At the time of preparing this manuscript, JSNVT worked for Aventis Pasteur MSD as UK Medical Director. He has subsequently moved to the Communicable Disease Surveillance Centre, Health Protection Agency, Colindale, London. The views expressed in this paper are not necessarily the views of Aventis Pasteur MSD or the Health Protection Agency.

\section{REFERENCES}

1 Neuzil KM, Mellen BG, Wright PF, et al. The effect of influenza on hospitalizations, outpatient visits, and courses of antibiotics in children. $N$ Engl J Med 2000;342:225-31.

2 Neuzil KM, Zhu Y, Griffin MR, et al. Burden of interpandemic influenza in children younger than 5 years: a 25 -year prospective study. $J$ Infect Dis 2002; 185: 147-52.

3 Nguyen-Van-Tam J. Epidemiology of influenza. In: Nicholson KG, Webster RG, Hay AJ, eds. Textbook of influenza. London: Blackwell Scientific Publications, 1998:181-206.

4 Ploin D, Liberas S, Thouvenot D, et al. Influenza burden in children newborn to eleven months of age in a pediatric emergency department during the peak of an influenza epidemic. Pediatr Infect Dis J 2003;22:S218-22.

5 O'Brien MA, Uyeki TM, Shay DK, et al. Incidence of outpatient visits and hospitalizations related to influenza in infants and young children. Pediatrics 2004; 113:585-93.

6 Izurieta HS, Thompson WW, Kramarz P, et al. Influenza and the rates of hospitalization for respiratory disease among infants and young children. N Engl J Med 2000;342:232-9.
7 Harper SA, Fukuda K, Uyeki TM, et al. Prevention and control of influenza: recommendations of the Advisory Committee on Immunization Practices (ACIP). MMWR Recomm Rep 2004;53:1-40.

8 Centers for Disease Control. Influenza vaccination recommendations: summary guide 2004-05. Available from http://www.cdc.gov/flu/ professionals/pdf/summary.pdf (accessed 19 September 2004).

9 Glezen WP. Influenza viruses. In: Feigin R, Cherry JD, eds. Textbook of pediatric infectious diseases. Pennsylvania: WB Saunders Company, 1998:2024-41.

10 Nicholson KG, Wood JM, Zambon M. Influenza. Lancet 2003;362:1733-45.

11 Rennels MB, Meissner HC. Technical report: Reduction of the influenza burden in children. Pediatrics 2002;110:e80.

12 World Health Organisation. Influenza vaccines: WHO position paper. Weekly epidemiological record. 12 July 2002;77: 229-40, Available from http://www.who.int/docstore/wer/pdf/2002/wer7728.pdf (accessed 9 June 2004)

13 World Health Organisation. Recommendations for influenza vaccine composition. Available from http://www.who.int/csr/disease/influenza/ vaccinerecommendations l/en/print.html (accessed 27 January 2004).

14 Munoz FM. Influenza virus infection in infancy and early childhood. Paediatr Respir Rev 2003;4:99-104.

15 Glezen WP, Couch RB. Interpandemic influenza in the Houston area, 197476. N Engl J Med 1978;298:587-92.

16 Nicholson KG, McNally T, Silverman M, et al. Influenza-related hospitalizations among young children in Leicestershire. Pediatr Infect Dis $J$ 2003;22:S228-30.

17 Laundy M, Ajayi-Obe E, Hawrami K, et al. Influenza A community-acquired pneumonia in East London infants and young children. Pediatr Infect Dis J 2003;22:S223-7

18 Principi N, Esposito S, Marchisio P, et al. Socioeconomic impact of influenza on healthy children and their families. Pediatr Infect Dis J 2003;22:S207-10.

19 Thompson WW, Shay DK, Weintraub E, et al. Mortality associated with influenza and respiratory syncytial virus in the United States. JAMA 2003;289:179-86

20 Glezen WP, Payne AA, Snyder DN, et al. Mortality and influenza. J Infect Dis 1982; 146:313-21.

21 Boseley S. New strain of Asian flu kills four children. The Guardian. Available from http://www.guardian.co.uk/uk_news/story/ 0\%2C3604\%2C1080426,00.html (accessed 9 January 2004)

22 Health Protection Agency. Influenza in the United Kingdom. C13. Available from http://www.hpa.org.uk/cdr/PDFfiles/2003/cdr4903.pdf laccessed 7 September 2004)

23 Summerfield C, Babb P. Social trends. Office of National Statistics. No. 33. London: The Stationary Office, 2003

24 Nafstad P, Hagen JA, Oie L, et al. Day care centers and respiratory health. Pediatrics 1999;103:753-8.

25 Silverstein M, Sales AE, Koepsell TD. Health care utilization and expenditures associated with child care attendance: a nationally representative sample. Pediatrics 2003;111:e371-5.

26 Hall CE, Cooney MK, Fox JP. The Seattle virus watch. IV. Comparative epidemiologic observations of infections with influenza $A$ and $B$ viruses, 1965-1969, in families with young children. Am J Epidemiol 1973;98:365-80

27 Fox JP, Cooney MK, Hall CE, et al. Influenzavirus infections in Seattle families, 1975-1979. II. Pattern of infection in invaded households and relation of age and prior antibody to occurrence of infection and related illness. Am J Epidemiol 1982;116:228-42

28 Jordan WS Jr, Denny FW Jr, Badger GF, et al. study of illness in a group of Cleveland families. XVII. The occurrence of Asian influenza. Am J Hyg 1958;68:190-212.

29 Hurwitz ES, Haber M, Chang A, ef al. Effectiveness of influenza vaccination of day care children in reducing influenza-related morbidity among household contacts. JAMA 2000;284:1677-82.

30 Monto AS, Davenport FM, Napier JA, et al. Modification of an outbreak of influenza in Tecumseh, Michigan by vaccination of schoolchildren. J Infect Dis 1970;122:16-25

31 Reichert TA, Sugaya N, Fedson DS, et al. The Japanese experience with vaccinating schoolchildren against influenza. $N$ Engl J Med 2001;344:889-96.

32 Fukuda K, Thompson WW, Cox N. Vaccinating Japanese schoolchildren against influenza. N Engl J Med 2001;344:1946-7.

33 Longini IM Jr, Koopman JS, Haber M, et al. Statistical inference for infectious diseases. Risk-specific household and community transmission parameters. Am J Epidemiol 1988;128:845-59.

34 Nichol KL. The efficacy, effectiveness and cost-effectiveness of inactivated influenza virus vaccines. Vaccine 2003;21:1769-75.

35 Neuzil KM, Dupont WD, Wright PF, et al. Efficacy of inactivated and coldadapted vaccines against influenza $A$ infection, 1985 to 1990: the pediatric experience. Pediatr Infect Dis J 2001;20:733-40.

36 Belshe RB, Mendelman PM, Treanor J, et al. The efficacy of live attenuated, cold-adapted, trivalent, intranasal influenzavirus vaccine in children. N Engl J Med 1998;338:1405-12.

37 Beyer WE, Palache AM, de Jong JC, et al. Cold-adapted live influenza vaccine versus inactivated vaccine: systemic vaccine reactions, local and systemic antibody response, and vaccine efficacy. A meta-analysis. Vaccine 2002;20:1340-53.

38 Turner D, Wailoo A, Nicholson K, et al. Systematic review and economic decision modelling for the prevention and treatment of influenza $A$ and $B$. Health Technol Assess 2003;7: iii-xiii, 1 .

39 World Health Organisation. WHO consultation on priority public health interventions before and during an influenza pandemic. Available from 
http://www.who.int/csr/disease/avian_influenza/en/final.pdf (accessed 24 September 2004).

40 Demmler GJ. Laboratory diagnosis of influenza: recent advances. Semin Pediatr Infect Dis 2002;13:85-9.

41 Harnden A, Brueggemann A, Shepperd S, et al. Near patient testing for influenza in children in primary care: comparison with laboratory test. BMJ 2003;326:480.

42 Uyeki TM. Influenza diagnosis and treatment in children: a review of studies on clinically useful tests and antiviral treatment for influenza. Pediatr Infect Dis J 2003:22:164-77.

43 Ellis JS, Zambon MC. Molecular diagnosis of influenza. Rev Med Virol 2002; 12:375-89

44 Sharma V, Dowd MD, Slaughter AJ, et al. Effect of rapid diagnosis of influenza virus type a on the emergency department management of febrile infants and toddlers. Arch Pediatr Adolesc Med 2002;156:41-3.

45 Esposito S, Marchisio P, Morelli P, et al. Effect of a rapid influenza diagnosis. Arch Dis Child 2003;88:525-6.

46 Peltola VT, Murti KG, McCullers JA. Secondary bacterial pneumonia following influenza. 22nd Annual Meeting of European Society for Paediatric Infectious Diseases, Tampere, May, 2004.

47 O'Brien KL, Walters MI, Sellman J, et al. Severe pneumococcal pneumonia in previously healthy children: the role of preceding influenza infection. Clin Infect Dis 2000:30:784-9.

48 Centers for Disease Control. Flu vaccine supply: 2003-04 season. Available from http://www.cdc.gov/flu/pdf/fluupdate.pdf (accessed 24 June 2004).

49 National Institute for Clinical Excellence. Full guidance on the use of zanamivir, oseltamivir and amantadine for the treatment of influenza. Available from http://www.nice.org.uk/pdf/58_Flu_fullguidance.pdf (accessed 5 January 2004).

50 Monto AS. The role of antivirals in the control of influenza. Vaccine 2003;21:1796-800

51 Centers for Disease Control. Antiviral agents for influenza: background information for clinicians, 16 December 2003. Available from hitp:// www.cdc.gov/flu/professionals/pdf/antiviralsbackground.pdf (accessed 5 January 2004)

52 Hayden FG. Perspectives on antiviral use during pandemic influenza. Philos Trans R Soc Lond B Biol Sci 2001:356:1877-84.

53 Hayden FG, Belshe RB, Clover RD, et al. Emergence and apparent transmission of rimantadine-resistant influenza A virus in families. N Engl J Med 1989;321:1696-702

54 Cooper NJ, Sutton AJ, Abrams KR, et al. Effectiveness of neuraminidase inhibitors in treatment and prevention of influenza $A$ and $B$ : systematic review and meta-analyses of randomised controlled trials. BMJ 2003;326:1235.

55 Matheson NJ, Symmonds-Abrahams M, Sheikh A, et al. Neuraminidase inhibitors for preventing and treating influenza in children. Cochrane Database Syst Rev 2003;CD002744.
56 Whitley RJ, Hayden FG, Reisinger KS, et al. Oral oseltamivir treatment of influenza in children. Pediatr Infect Dis J 2001;20:127-33.

57 Kaiser L, Wat C, Mills T, et al. Impact of oseltamivir treatment on influenzarelated lower respiratory tract complications and hospitalizations. Arch Intern Med 2003; 163:1667-72.

58 Centers for Disease Control. Influenza antiviral medications: interim chemoprophylaxis and treatment guidelines, 16 December 2003. Available from http://www.cdc.gov/flu/professionals/pdf/antiviralguid.pdf (accessed 5 January 2004)

59 National Institute for Clinical Excellence. Full guidance on the use of oseltamivir and amantadine for the prophylaxis of influenza, Available from http://www.nice.org.uk/pdf/67_Flu_prophylaxis_guidance.pdf (accessed 5 January 2004).

60 Ruben FL. Inactivated influenza virus vaccines in children. Clin Infect Dis 2004;38:678-88.

61 British Medical Association, Royal Pharmaceutical Society of Great Britain Immunological products and vaccines. In: British Medical Formulary 45, March 2003:588-9.

62 Department of Health. Update on the influenza and pneumococcal immunisation programmes. Available from http://www.dh.gov.uk/ assetRoot/04/08/73/40/04087340.pdf (accessed 6 September 2004).

63 Herzog C, Metcalfe IC, Schaad UB. Virosome influenza vaccine in children. Vaccine 2002;20(suppl 5):B24-8.

64 Kanra G, Marchisio P, Feiterna-Sperling C, et al. Comparison of immunogenicity and tolerability of a virosome-adjuvanted and a split influenza vaccine in children. Pediatr Infect Dis J 2004;23:300-6.

65 Health Protection Agency. HPA national surveillance of influenza weekly reports. Report 16-14 January 2004. Available from http:// www.hpa.org.uk/infections/topics_az/influenza/Activity0304/Text/ report 16.pdf (accessed 21 January 2004).

66 World Health Organisation. Influenza vaccine for the northern hemisphere 2003-2004: additional information, 19 December 2003. Available from http://www.who.int/csr/disease/influenza/vaccine2003/en/index.html (accessed 5 January 2004).

67 World Health Organisation. Recommendations for influenza vaccine composition: northern hemisphere 2004-2005. Available from http:// www.who.int/csr/disease/influenza/vaccinerecommendations 1/en/ (accessed 13 February 2004).

68 Department of Health. Influenza. In: Green book. Available from http:// www.dh.gov.uk/assetRoot/04/08/87/93/04088793.pdf (accessed 9 September 2004)

69 Poehling KA, Speroff T, Dittus RS, et al. Predictors of influenza virus vaccination status in hospitalized children. Pediatrics 2001;108:e99.

70 van Essen GA, Palache AM, Forleo E, et al. Influenza vaccination in 2000 recommendations and vaccine use in 50 developed and rapidly developing countries. Vaccine 2003;21:1780-5.

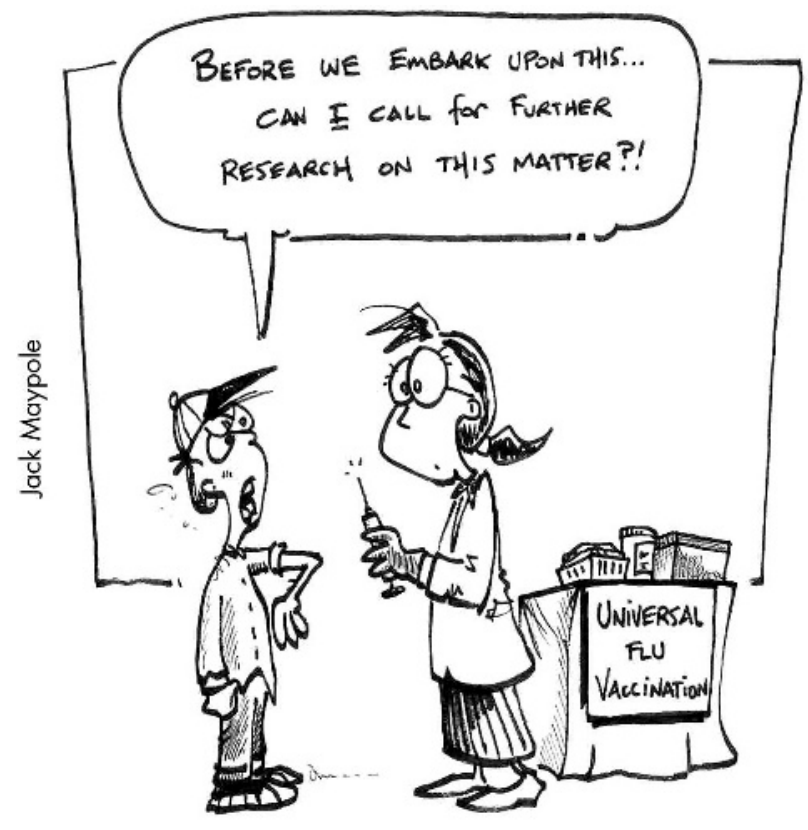

www.archdischild.com 